\title{
THE BALLISTOCARDIOGRAM IN THE DIAGNOSIS OF CORONARY ARTERIAL DISEASE
}

\author{
BY \\ E. G. WADE, R. M. FULTON, AND J. MACKINNON \\ From the University Department of Cardiology, Manchester Royal Infirmary \\ Received April 7, 1955
}

Deciding whether chest pain is of cardiac origin is sometimes one of the most difficult problems confronting the cardiologist. Although the electrocardiogram is generally abnormal following prolonged cardiac pain, it affords no help in over 50 per cent of cases of angina of effort (Wade and Morgan Jones, 1951), while the more rigorous methods of electrocardiographic investigation such as the two-step exercise test (Master, 1935) or the anoxæmia test (Levy et al., 1940), which depend upon the production of acute myocardial ischæmia, are not entirely free from risk.

A new approach to this problem was made by Starr and Wood (1943) who applied the ballistocardiograph to the study of 55 cases of acute infarction or chronic angina pectoris. This instrument, which measures some of the forces transmitted to the body by cardiac contraction, had first been utilized by Henderson in 1905 and again by Abrahamson in 1933, but its fuller development is due to the work of Starr and his co-workers (Starr et al., 1939).

Within recent years several papers have been published, mainly in America, concerning the use of the ballistocardiograph in the study of coronary arterial disease and most workers have concluded that it is a useful diagnostic aid. It has not, however, been exploited by cardiologists on this side of the Atlantic and apart from the paper of Jacobs (1954) no parallel studies have been reported in Great Britain. It is the purpose of this paper to report the results of a ballistocardiographic survey of 197 patients considered to be suffering from coronary vascular disease; to evaluate the ballistocardiograph as a diagnostic aid in this condition, and to contrast it with the electrocardiograph. Another 38 patients of corresponding age group but presumably free from cardiovascular disease have also been examined.

\section{MATERIAL AND METHODS}

The material consisted of 235 patients attending the University Department of Cardiology at the Royal Infirmary, Manchester, during 1952, 1953, and 1954. Thirty-eight were considered to be free from cardiovascular disease: the remaining 197 were selected because they complained of chest pain having the typical features of cardiac pain in accordance with the criteria set out by Wade and Morgan Jones (1951). Clinical myocardial infarction was considered to have occurred if cardiac pain had at some time persisted for more than one hour, for detailed histological examination of the myocardium has usually revealed infarction if cardiac pain has persisted for more than thirty minutes (Snow, 1955). Cases of valvular disease were excluded. The patients were divided clinically into three groups.

(1) Pure angina of effort.

(2) Angina of effort complicated by clinical myocardial infarction.

(3) Clinical myocardial infarction without angina of effort.

In addition to the usual clinical examination, all patients were screened and an electrocardiogram comprising standard leads, augmented unipolar limb leads, and six chest leads in the positions one to six 
using the central terminal of Wilson, was taken on the same day as the ballistocardiographic study. The electrocardiograms were classified in accordance with generally accepted criteria. These criteria have been set out in full by Wade and Morgan Jones but may be briefly restated.

(1) The presence of abnormal $Q$ waves or the absence of $R$ waves together with changes in the S-T segment or inversion of the $T$ wave in leads facing the left ventricle, was regarded as diagnostic of infarction.

(2) Records showing abnormal $Q$ waves or absent $R$ waves but without corresponding abnormalities of ST-T; or $\mathrm{T}$ wave inversion of a form and distribution not explicable by left ventricular enlargement, digitalis, etc. were classified as suspected infarction.

(3) Records showing S-T depression and diphasic T waves over the left præcordium, with or without delay in the onset of the intrinsic deflection, were classified as abnormal but non-specific. Conduction defects alone were also put in this group.

(4) Normal records.

It is beyond the scope of this paper to discuss in detail the merits and demerits of the various types of ballistocardiographic beds; for a good review, reference should be made to Gubner et al. (1953). It appears probable that the high-frequency undamped Starr bed is the most suitable for detecting qualitative changes, for in the low-frequency critically damped bed of the Nickerson type (Nickerson and Curtis, 1954) the frequency response decays too quickly leading to reduced amplitude, phase displacement, and increased duration (Rappaport et al., 1953). The low-frequency, critically damped bed possesses certain advantages if it is desired to estimate the cardiac output. Our ballistocardiograms were taken on a high-frequency undamped instrument of the type described by Starr et al. (1939) having a natural frequency of $11 \mathrm{c} / \mathrm{s}$. It was calibrated so that a longitudinal force of $500 \mathrm{~g}$. displaced the spot $1 \mathrm{~cm}$. The movements of the bed were recorded electronically together with a simultaneous electrocardiogram. The studies were made not less than two hours after a meal and patients rested for at least 20 minutes before the records were taken. The instrument was recalibrated on each occasion.

\section{THE INTERPRETATION OF THE BALLISTOCARDIOGRAMS}

Ballistocardiography is still in its early and experimental stages and the approach remains empirical. If the results are to have any meaning it is therefore imperative that the criteria used in the analysis of the records should be clearly set forth.

The normal ballistocardiogram complex consists of four major and three minor waves (Fig. 1A). The nomenclature has been laid down by the Committee on Ballistocardiographic Terminology (Starr et al., 1953). It is generally accepted that the major waves I, J, and $\mathrm{K}$ are produced by the recoil of ventricular ejection, impact in the arch of the aorta and the pulmonary artery together with recoil from acceleration down the descending aorta, and impact in the iliac and femoral arteries respectively (Starr et al., 1939; Hamilton et al., 1945; Starr et al., 1950). The genesis of the remaining major wave $\mathbf{H}$, is less certain. It is related in time to the fourth component of the first heart sound (Thompson et al., 1953), and therefore to the onset of isometric contraction (Starr and Wood, 1943; Tannenbaum et al., 1952; Tannenbaum et al., 1954). It may well be affected by movements of blood within the ventricles at this stage of the cycle. The minor waves $L, M$, and $N$ are related to diastolic events and are of less importance. There is a phasic variation in the amplitude of the complexes during the respiratory cycle due to changes in venous return, the complexes being larger in inspiration (Fig. 2A).

The ballistocardiogram may be affected quantitatively by a general slowing of the rate of cardiac ejection, a shift of the cardiac ejection curve to the "right", for it has been conclusively demonstrated that the event most closely concerned with the genesis of the ballistocardiogram is the rate at which the ventricles can accelerate their contents (Starr et al., 1950). Cadaver experiments showed that the ballistocardiogram consists of the algebraic sum of two curves, one derived from ventricular discharge and the other from events happening in the aorta and to a lesser extent in the pulmonary artery (Starr et al., 1950). It is therefore a measure of cardiac " force ", and Starr and Schnabel (1954) have found that $\sqrt{\bar{I}+\mathrm{J}}$ corrected for surface area is closely related to the maximum velocity of ejection. Despite this correlation, force in this context appears to us to be a 


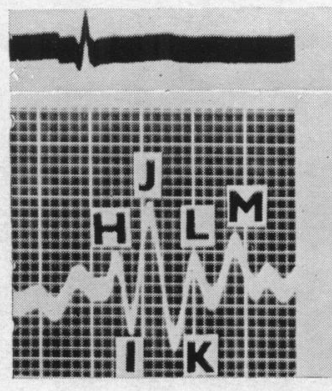

A

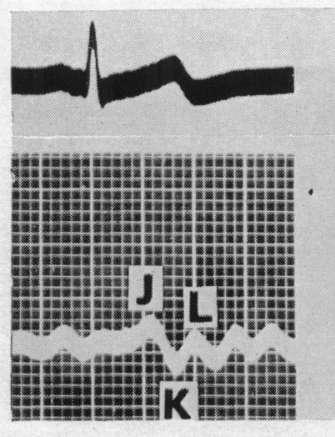

$\mathrm{D}$

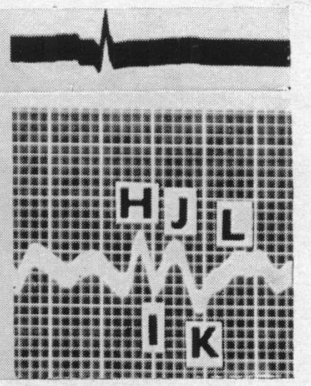

B

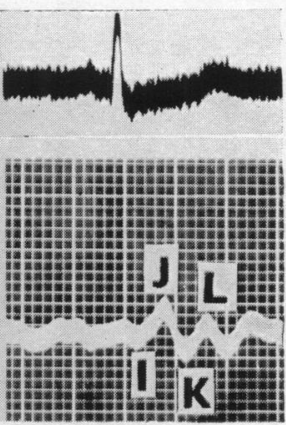

$\mathrm{C}$

Fig. 1.-Normal and abnormal ballistocardiogram complexes. (A) is a normal complex; (B), (C), and (D) are abnormal complexes of the " early $\mathrm{M}$," "late M," and "late downstroke " types respectively.

relative concept incorporating the resistance against which the force is acting. It is also possible that the anatomical position of the heart may affect the amplitude of I-J. Using a table capable of movement in both head/foot and lateral planes, Dock (1954) found that in hypertension a diminution in the amplitude of the major waves in the head/foot direction was accompanied by a reciprocal increase in the lateral plane; this was not so in the abnormal records of infarction. Tannenbaum et al. (1954) using a three-plane spatial vector-ballistocardiogram, also concluded that the amplitude of $\mathbf{H}, \mathbf{I}$, and $\mathbf{J}$ could be influenced by the anatomical position of the heart. For these reasons we have not used equations of the type devised by Starr et al. (1950) and Starr and Schnabel (1954) for the calculation of cardiac force from the ballistocardiogram.

Qualitative changes provide evidence of irregular ejection and therefore by inference of myocardial disease, and we have regarded records as abnormal only when qualitatively abnormal complexes were present. In deciding what constitutes an abnormal complex we have followed the recommendations of Starr and Wood (1943). They identified three main types of abnormal complex, the " early $M$ " type, the "late $M$ " type, and the " early downstroke" type. The early $M$ complex (Fig. 1B) is due to exaggeration of $H$ together with a small $I$ and low $J$ waves. In the late $\mathbf{M}$ complex $\mathbf{J}$ is split and $\mathbf{K}$ almost absent while in the late downstroke type $\mathbf{J}$ is absent and $K$ is delayed and deep (Fig. 1C and 1D). The nature of the deformation of the ejection curve responsible for these complexes has been extensively investigated in cadaver experiments (Starr et al., 1950). In the more severe disease states the complexes may become virtually unrecognizable. Abnormal complexes tend to appear first in the expiratory phase. The reasons for this are uncertain but 
A
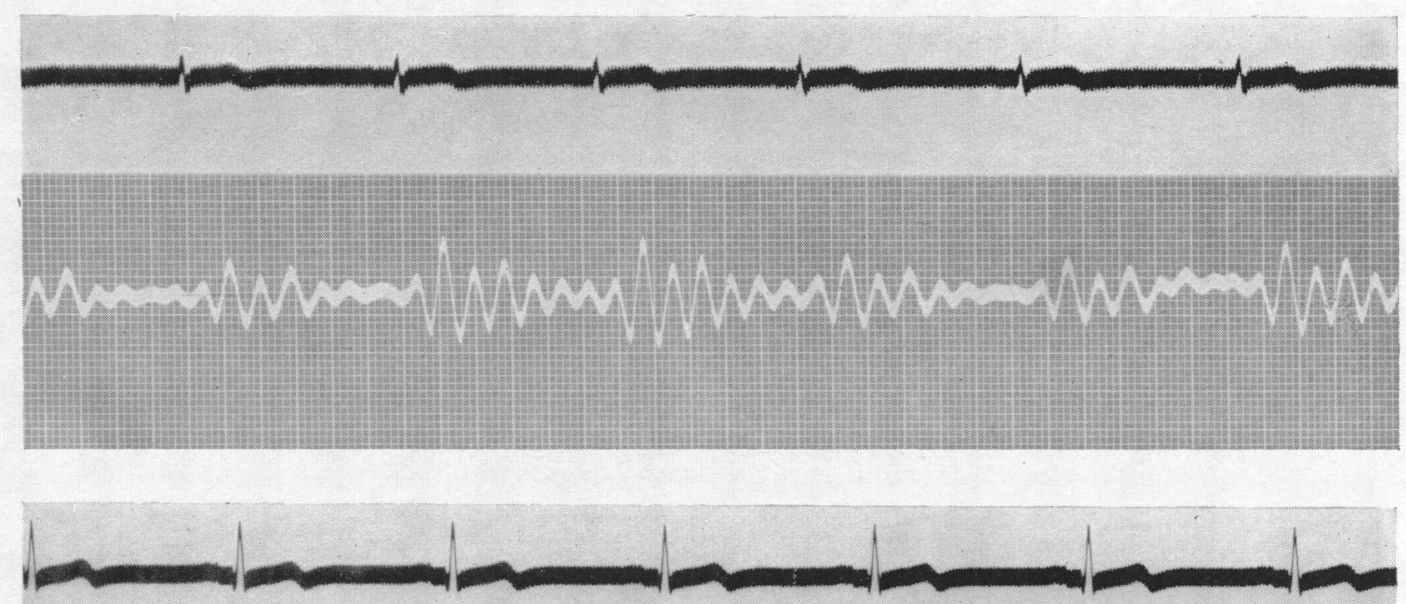

B
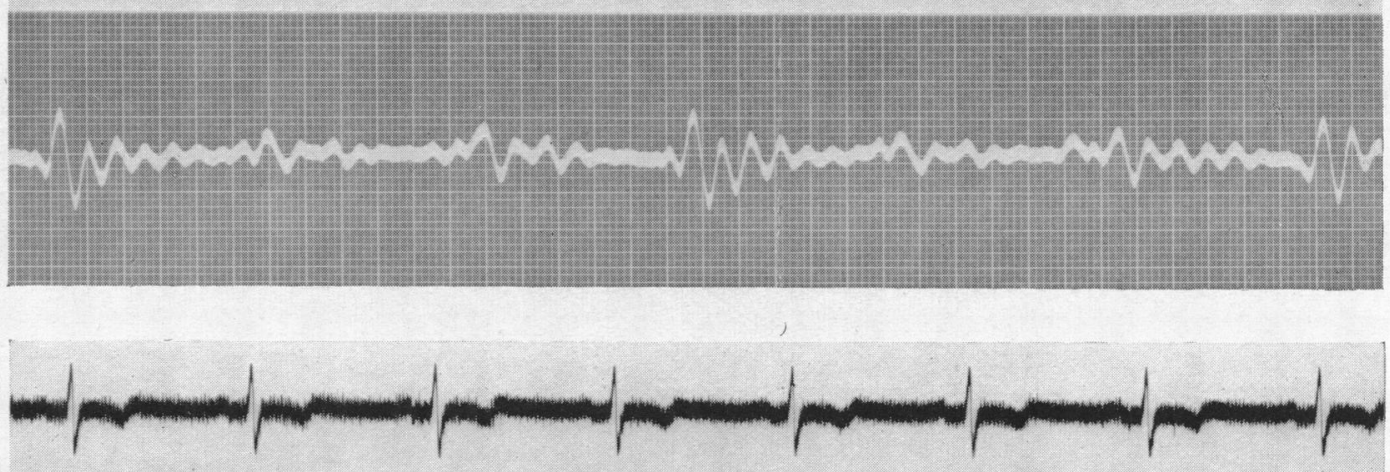

C
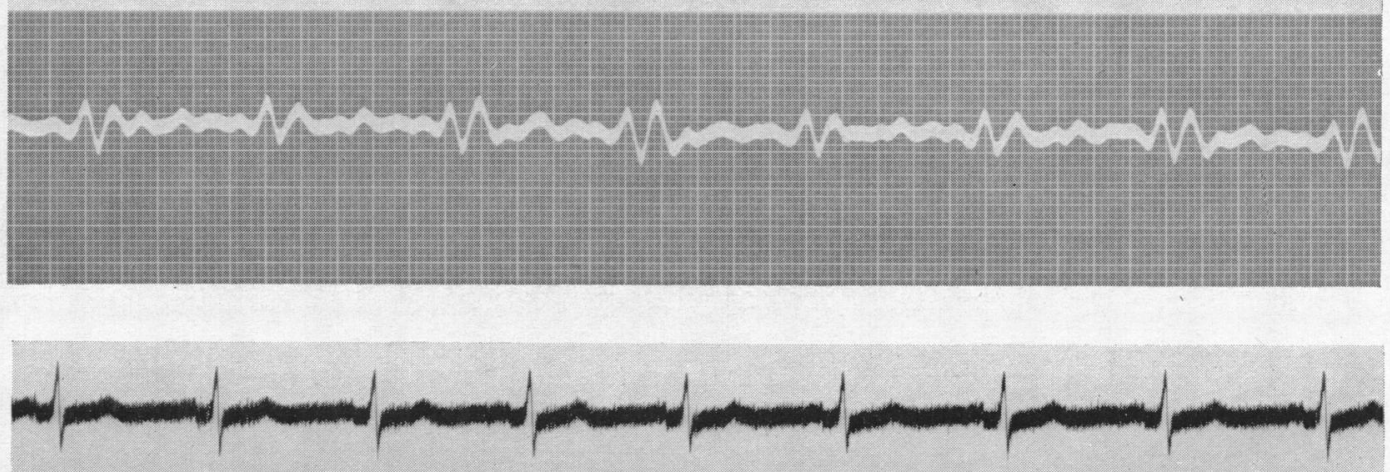

$\mathrm{D}$

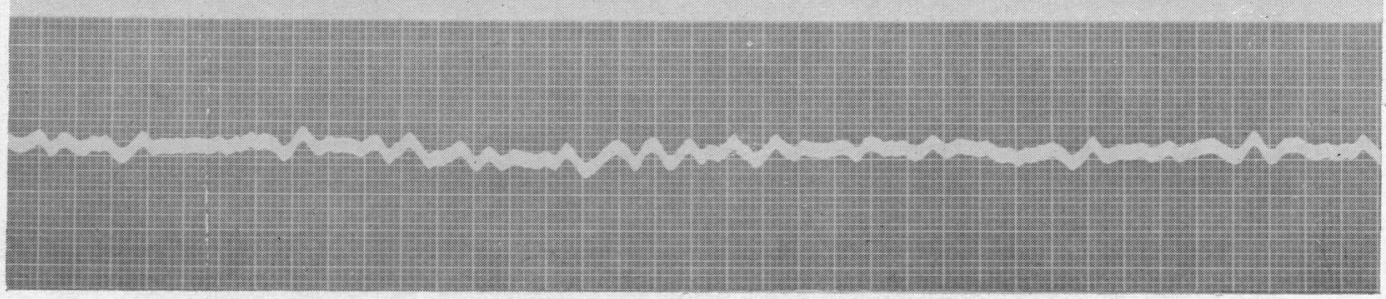

FIG. 2.-Normal and abnormal ballistocardiograms. (A) is a normal record showing the customary variation in complex size during respiration. The remaining records are abnormal. (B) shows early $M$ complexes in expiration and is classified as Grade I. In (C) all the complexes are abnormal but repeatability is maintained; this is classified as Grade II. In (D) the complexes do not show a regular pattern and this is regarded as Grade III. 


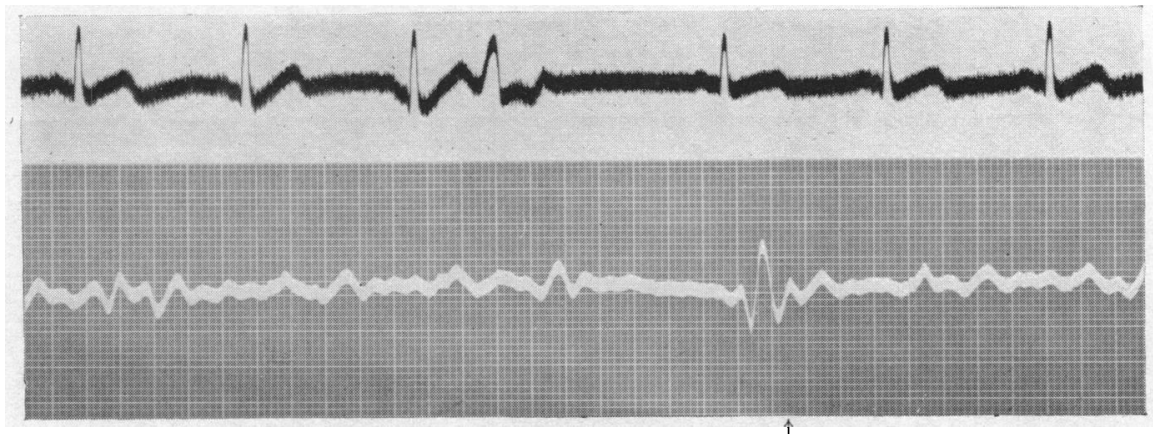

FIG. 3.-The effect of improved ventricular filling on the ballistocardiogram. The only normal complex, marked with an arrow, is that following a compensatory pause.

variations in venous return may be important. That improved ventricular filling may be responsible for producing a normal complex in an otherwise abnormal record is well shown in Fig. 3 in which the only normal complexes were those following the compensatory pause after an extrasystole. Any system must therefore take into account the proportion of abnormal complexes in the record.

To meet these various requirements we have therefore used the following classification. A ballistocardiogram was regarded as abnormal if any of the three types of abnormal complex described by Starr and Wood (1943) were present in the strip of recording. It was then sub-divided into grades of abnormality as follows.

Grade I. Abnormal complexes in expiration only.

Grade II. All complexes abnormal but definable and repeatable.

Grade III. Bizarre records in which repeatability is lost or in which the complexes can only be defined with the aid of the timing electrocardiogram.

Typical examples of each of these three grades are illustrated in Fig. 2 B, C, and D.

\section{RESULTS}

Cases of Coronary Arterial Disease. The results in the various clinical groups are given in Tables I, II, and III. The ballistocardiographic is more constant than the electrocardiographic pattern, the major B.C.G. difference between the three clinical groups being the higher proportion of

TABLE I

ANgina of EFFort without Clinical Infarction

\begin{tabular}{|c|c|c|c|c|c|c|c|c|c|}
\hline \multirow{2}{*}{$\begin{array}{l}\text { No. of } \\
\text { cases }\end{array}$} & \multirow{2}{*}{$\begin{array}{l}\text { Age } \\
\text { group }\end{array}$} & \multicolumn{4}{|c|}{ Electrocardiogram } & \multicolumn{4}{|c|}{ Ballistocardiogram } \\
\hline & & Normal & $\begin{array}{c}\text { Non- } \\
\text { specific }\end{array}$ & $\begin{array}{l}\text { Suspected } \\
\text { infarction }\end{array}$ & Infarct & Normal & Gd. I & Gd. II & Gd. III \\
\hline $\begin{array}{l}23 \\
54 \\
28\end{array}$ & $\begin{array}{c}<50 \\
50-59 \\
>60\end{array}$ & $\begin{array}{l}14 \\
29 \\
16\end{array}$ & $\begin{array}{r}5 \\
19 \\
9\end{array}$ & $\begin{array}{l}1 \\
3 \\
1\end{array}$ & $\begin{array}{l}3 \\
3 \\
2\end{array}$ & $\begin{array}{r}11 \\
11 \\
1\end{array}$ & $\begin{array}{r}9 \\
23 \\
11\end{array}$ & $\begin{array}{r}2 \\
18 \\
13\end{array}$ & $\begin{array}{l}1 \\
2 \\
3\end{array}$ \\
\hline 105 & & $\begin{array}{c}59 \\
(56 \%)\end{array}$ & $\begin{array}{c}33 \\
(31.5 \%)\end{array}$ & $\begin{array}{c}5 \\
(4 \cdot 8 \%)\end{array}$ & $\begin{array}{c}7 \\
(7 \cdot 7 \%)\end{array}$ & $\begin{array}{c}23 \\
(21 \cdot 9 \%)\end{array}$ & $\begin{array}{c}43 \\
(41 \%)\end{array}$ & $\begin{array}{c}33 \\
(31 \cdot 4 \%)\end{array}$ & $\begin{array}{c}6 \\
(5.7 \%\end{array}$ \\
\hline
\end{tabular}

Grade III records amongst the cases of myocardial infarction. Grade III records tend to be found more often shortly after infarction (Table IV) and it was observed that in 13 cases in which a ballistocardiogram was recorded within three months of infarction and repeated after a further three to six months, three of the four initial Grade III records had improved to Grade II or Grade I. 
TABLE II

Clinical Infarction without Angina of Effort

\begin{tabular}{|c|c|c|c|c|c|c|c|c|c|}
\hline \multirow{2}{*}{$\begin{array}{l}\text { No. of } \\
\text { cases }\end{array}$} & \multirow{2}{*}{$\underset{\text { group }}{\text { Age }}$} & \multicolumn{4}{|c|}{ Electrocardiogram } & \multicolumn{4}{|c|}{ Ballistocardiogram } \\
\hline & & Normal & $\begin{array}{l}\text { Non- } \\
\text { specific }\end{array}$ & $\begin{array}{l}\text { Suspected } \\
\text { infarction }\end{array}$ & Infarct & Normal & Gd. I & Gd. II & Gd. III \\
\hline $\begin{array}{r}20 \\
12 \\
6\end{array}$ & $\begin{array}{c}<50 \\
50-59 \\
>60\end{array}$ & $\begin{array}{l}3 \\
1 \\
1\end{array}$ & $\begin{array}{l}2 \\
2 \\
0\end{array}$ & $\begin{array}{l}1 \\
3 \\
0\end{array}$ & $\begin{array}{r}14 \\
6 \\
5\end{array}$ & $\begin{array}{l}8 \\
0 \\
0\end{array}$ & $\begin{array}{l}7 \\
5 \\
0\end{array}$ & $\begin{array}{l}1 \\
4 \\
4\end{array}$ & $\begin{array}{l}4 \\
3 \\
2\end{array}$ \\
\hline 38 & & $\begin{array}{c}5 \\
(13 \%)\end{array}$ & $\begin{array}{c}4 \\
(10 \%)\end{array}$ & $\begin{array}{c}4 \\
(10 \%)\end{array}$ & $\begin{array}{c}25 \\
(67 \%)\end{array}$ & $\begin{array}{c}8 \\
(21 \%)\end{array}$ & $\begin{array}{c}12 \\
(31 \cdot 6 \%)\end{array}$ & $\begin{array}{c}9 \\
(23.7 \%)\end{array}$ & $\begin{array}{c}9 \\
(23.7 \%)\end{array}$ \\
\hline
\end{tabular}

TABLE III

Angina of Effort with Clinical Infarction

\begin{tabular}{|c|c|c|c|c|c|c|c|c|c|}
\hline \multirow{2}{*}{$\begin{array}{l}\text { No. of } \\
\text { cases }\end{array}$} & \multirow{2}{*}{$\begin{array}{c}\text { Age } \\
\text { group }\end{array}$} & \multicolumn{4}{|c|}{ Electrocardiogram } & \multicolumn{4}{|c|}{ Ballistocardiogram } \\
\hline & & Normal & $\begin{array}{c}\text { Non- } \\
\text { specific }\end{array}$ & $\begin{array}{l}\text { Suspected } \\
\text { infarction }\end{array}$ & Infarct & Normal & Gd. I & Gd. II & Gd. III \\
\hline $\begin{array}{l}16 \\
27 \\
11\end{array}$ & $\begin{array}{c}<50 \\
50-59 \\
>60\end{array}$ & $\begin{array}{l}1 \\
7 \\
1\end{array}$ & $\begin{array}{l}2 \\
6 \\
2\end{array}$ & $\begin{array}{l}2 \\
5 \\
4\end{array}$ & $\begin{array}{r}11 \\
9 \\
4\end{array}$ & $\begin{array}{l}2 \\
5 \\
0\end{array}$ & $\begin{array}{r}5 \\
10 \\
4\end{array}$ & $\begin{array}{r}3 \\
10 \\
6\end{array}$ & $\begin{array}{l}6 \\
2 \\
1\end{array}$ \\
\hline 54 & & $\begin{array}{c}9 \\
(17 \%)\end{array}$ & $\begin{array}{c}10 \\
(18.4 \%)\end{array}$ & $\begin{array}{c}11 \\
(20 \cdot 4 \%)\end{array}$ & $\begin{array}{c}24 \\
(44.4 \%)\end{array}$ & $\begin{array}{c}7 \\
(13 \cdot \%)\end{array}$ & $\begin{array}{c}19 \\
(35 \%)\end{array}$ & $\begin{array}{c}19 \\
(35 \%)\end{array}$ & $\begin{array}{c}9 \\
(17 \%)\end{array}$ \\
\hline
\end{tabular}

TABLE IV

The Proportion of Abnormal Ballistocardiograms in Relation to the Time after Clinical Myocardial Infarction

\begin{tabular}{|c|c|c|c|c|c|}
\hline \multirow{2}{*}{$\begin{array}{c}\text { Time } \\
\text { (months) }\end{array}$} & \multirow{2}{*}{$\begin{array}{l}\text { No. of } \\
\text { cases }\end{array}$} & \multicolumn{4}{|c|}{ Ballistocardiogram } \\
\hline & & Normal & Gd. I & Gd. II & Gd. III \\
\hline $\begin{array}{l}<3 \\
>3\end{array}$ & $\begin{array}{l}39 \\
62\end{array}$ & $\begin{array}{c}6 \\
(15.4 \%) \\
14 \% \\
(22.6 \%)\end{array}$ & $\begin{array}{c}8 \\
(20.5 \%) \\
24 \\
(38.7 \%)\end{array}$ & $\begin{array}{c}14 \\
(35.9 \%) \\
19 \% \\
(30.6 \%)\end{array}$ & $\begin{array}{c}11 \\
28 \cdot 2 \%) \\
5 \\
(8 \cdot 1 \%)\end{array}$ \\
\hline
\end{tabular}

Case Report (221). A man of 48 experienced an attack of severe crushing retrosternal pain lasting several hours; his doctor reported that he was shocked. Three days later there were no abnormal findings, the electrocardiogram was within normal limits but the ballistocardiogram was Grade III. Six months later he had made a complete recovery and the ballistocardiogram had improved to Grade I (Fig. 4).

There tend to be more abnormal ballistocardiograms in the older age groups and this is well shown in the total figures (Table V). There is only one normal ballistocardiogram in the 45 patients over 60 years of age but no corresponding increased frequency of abnormalities in the electrocardiogram pattern. 
II

III

R

L

$\mathrm{F}$
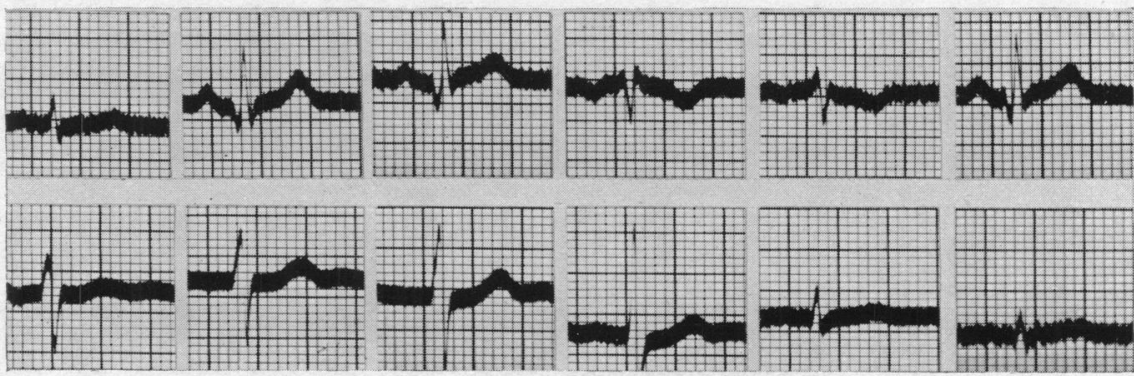

V1

V2

V3

V4
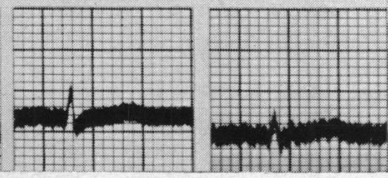

V5

V6

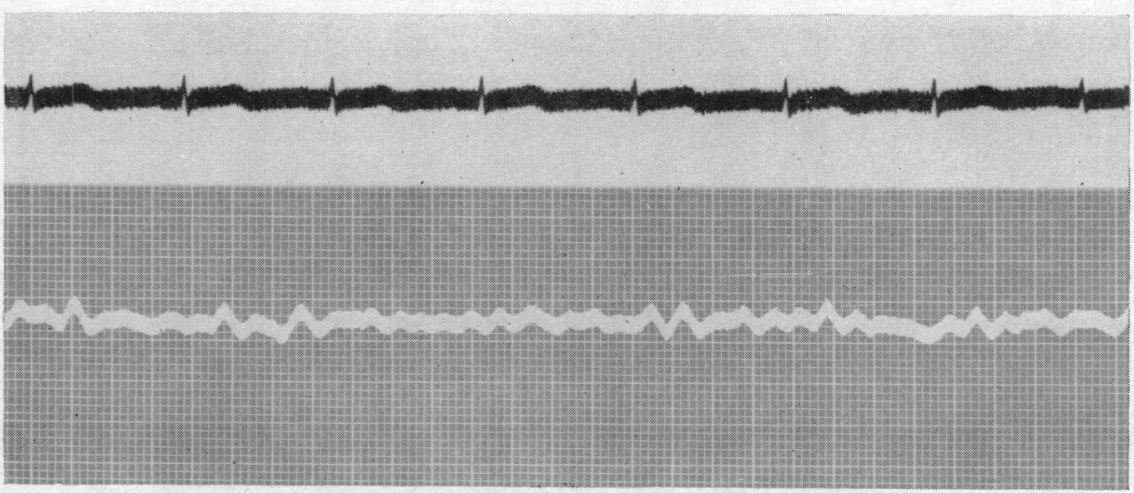

Electro- and ballisto-cardiograms 3 days after infarct. (Gd. III)

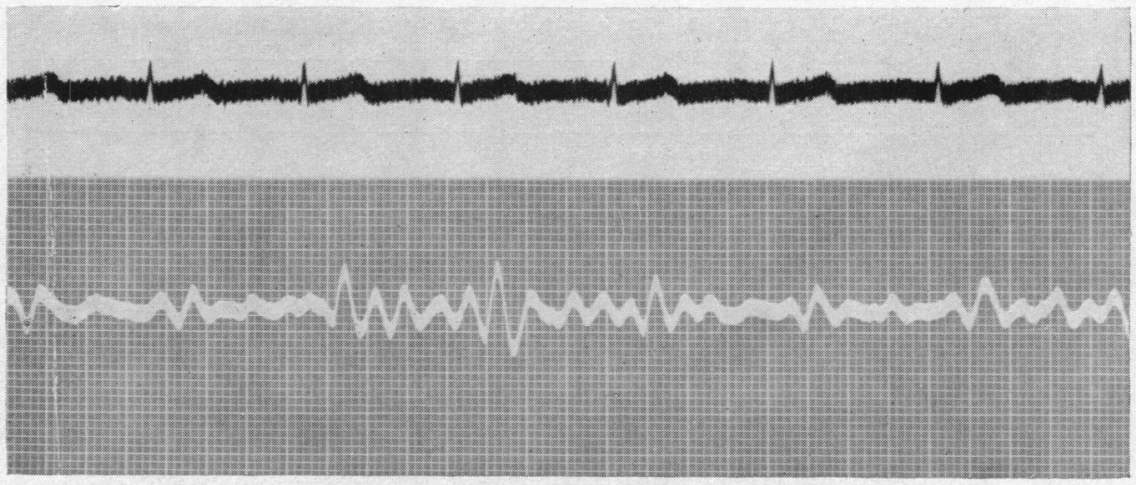

Ballistocardiogram 6 months after infarct. (Gd. I)

Fig. 4.-Grossly abnormal ballistocardiogram shortly after infarction. The electrocardiogram and the upper ballistocardiogram were taken three days after a prolonged attack of typical cardiac pain. Apart from a doubtful $Q$ wave in the foot lead and small voltage complexes over the left præcordium the electrocardiogram is normal but the ballistocardiogram is Grade III. Six months later the ballistocardiogram had improved to Grade I and the patient was symptom free. 
TABLE V

All Cases of Coronary Arterial Disease

\begin{tabular}{|c|c|c|c|c|c|c|c|c|c|}
\hline \multirow{2}{*}{$\begin{array}{l}\text { No. of } \\
\text { cases }\end{array}$} & \multirow{2}{*}{$\underset{\text { group }}{\text { Age }}$} & \multicolumn{4}{|c|}{ Electrocardiogram } & \multicolumn{4}{|c|}{ Ballistocardiogram } \\
\hline & & Normal & $\begin{array}{l}\text { Non- } \\
\text { specific }\end{array}$ & $\begin{array}{l}\text { Suspected } \\
\text { infarction }\end{array}$ & Infarct & Normal & Gd. I & Gd. II & Gd. III \\
\hline $\begin{array}{l}59 \\
93 \\
45\end{array}$ & $\begin{array}{c}<50 \\
50-59 \\
>60\end{array}$ & $\begin{array}{l}18 \\
37 \\
18\end{array}$ & $\begin{array}{r}9 \\
27 \\
11\end{array}$ & $\begin{array}{r}4 \\
11 \\
5\end{array}$ & $\begin{array}{l}28 \\
18 \\
11\end{array}$ & $\begin{array}{r}21 \\
16 \\
1\end{array}$ & $\begin{array}{l}21 \\
38 \\
15\end{array}$ & $\begin{array}{r}6 \\
32 \\
23\end{array}$ & $\begin{array}{r}11 \\
7 \\
6\end{array}$ \\
\hline 197 & & $\begin{array}{c}73 \\
(37 \%)\end{array}$ & $\begin{array}{c}47 \\
(10.8 \%)\end{array}$ & $\begin{array}{c}20 \\
(10.2 \%)\end{array}$ & $\begin{array}{c}57 \\
(29 \%)\end{array}$ & $\begin{array}{c}38 \\
(19 \cdot 3 \%)\end{array}$ & $\begin{array}{c}74 \\
(37.6 \%)\end{array}$ & $\begin{array}{c}61 \\
(31 \%)\end{array}$ & $\begin{array}{c}24 \\
(12 \cdot 1 \%)\end{array}$ \\
\hline
\end{tabular}

That ballistocardiogram and electrocardiogram measure differing aspects of cardiac function and are not therefore interdependent is illustrated by the following cases.

Case Report (23). A man of 66 had experienced typical angina of effort for six months. A month previously he had had an attack of pain at rest lasting two hours. On examination there were no abnormal findings, the electrocardiogram showed anteroseptal ischæmia but the ballistocardiogram was within normal limits. One year later he was unchanged; an electrocardiogram was now within normal limits but the ballistocardiogram was abnormal.

Case Report (26). A man of 39 had suffered from typical angina of effort for four months. On examination there were no abnormal findings. The electrocardiogram was normal but the ballistocardiogram was Grade II. Three months later he had a clinical infarction. A year later his exercise tolerance was the same as when first seen; the electrocardiogram now showed a posterior infarct but the ballistocardiogram was still Grade II (Fig. 5).

The lack of close relation between the electrocardiographic and ballistocardiographic patterns is brought out in Table VI. In this table the effects of age are discounted and the ballistocardiogram

TABLE VI

Cases of Coronary Arterial Disease Classified by the Electrocardiogram

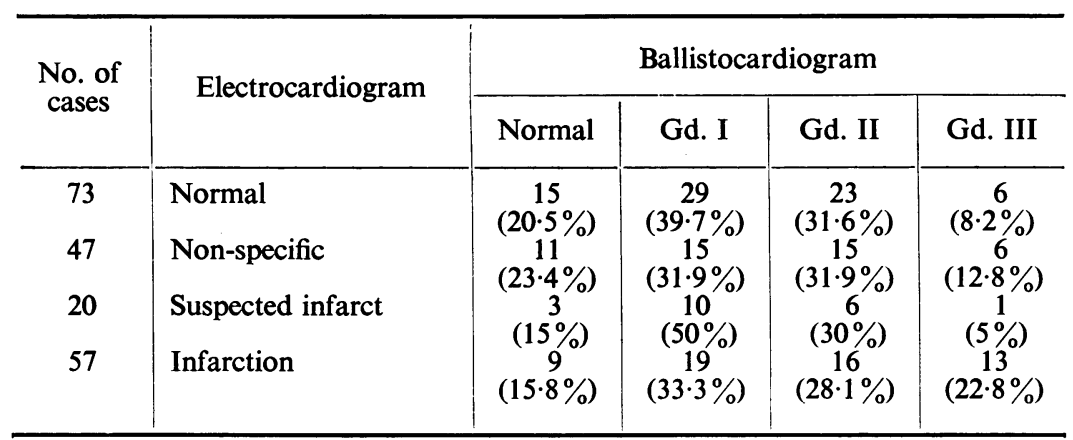

results are very similar in the differing electrocardiographic groups. As already noted, there is a higher proportion of Grade III records in the infarction group possibly explicable in part by the time relation to the infarction. Approximately the same ballistocardiographic results were found in those cases complicated by systemic hypertension despite the very different electrocardiographic pattern (Table VII). There appeared to be a general, but not very close, relation between the grade of the ballistocardiogram and the severity of the symptoms. Thus on review in six to twelve months after the first record, over 50 per cent of the patients had not changed clinically irrespective 
$\mathrm{L}$

F

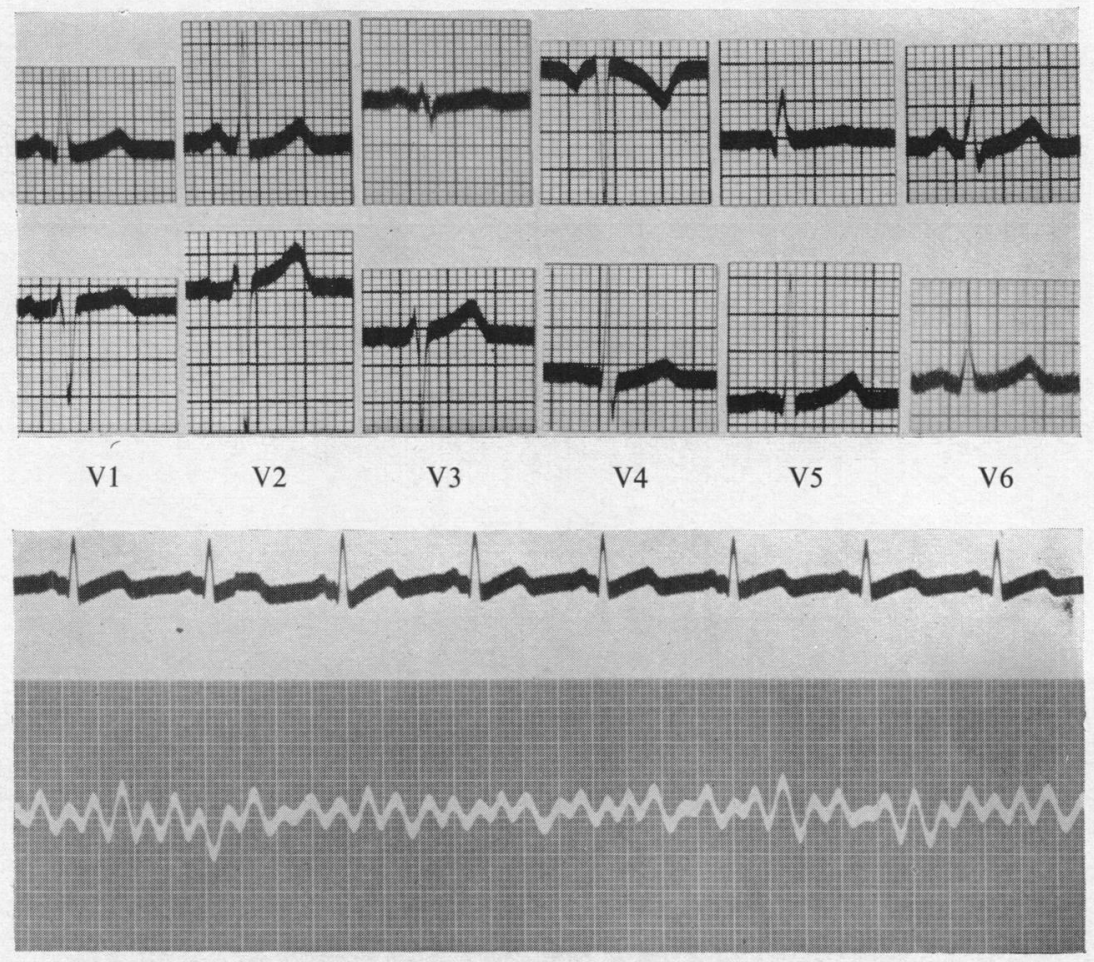

E.C.G. and B.C.G. 3 months before infarction (B.C.G. Gd. II).
I
II
III
$\mathrm{R}$
L
$\mathrm{F}$
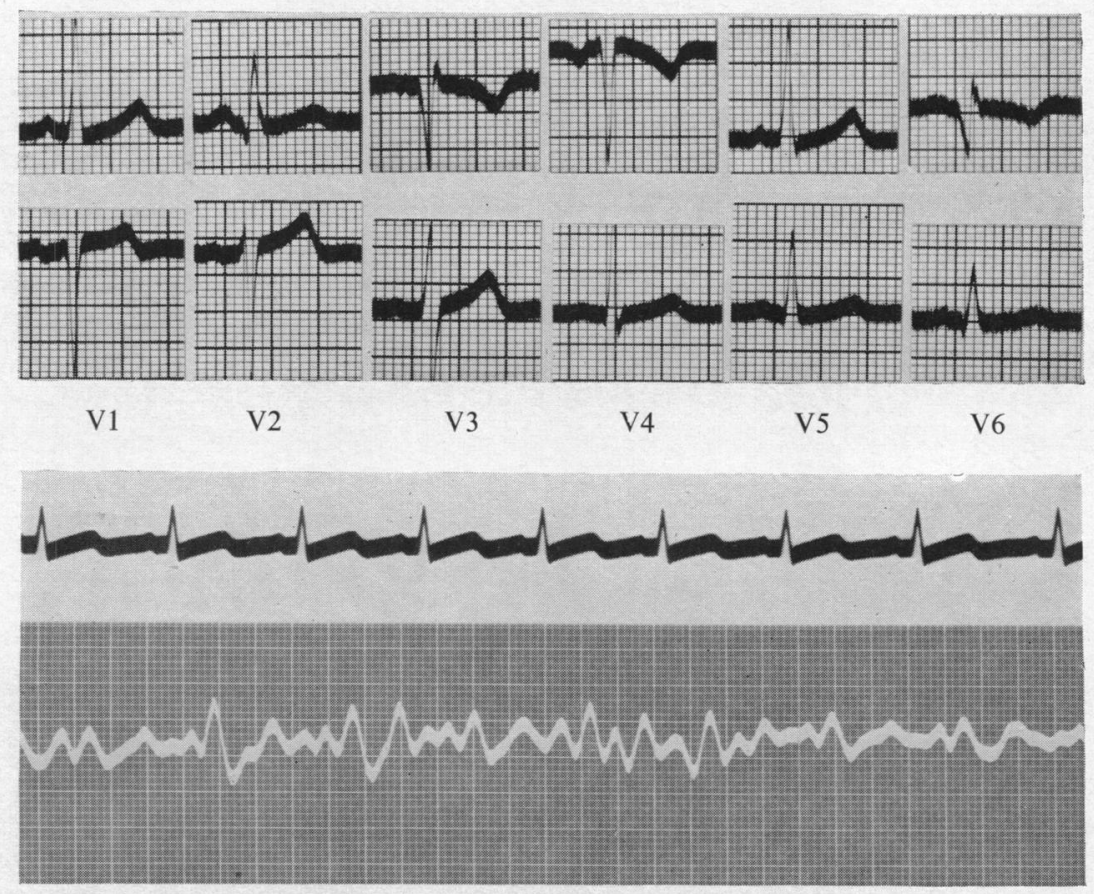

E.C.G. and B.C.G. 6 months after infarction (B.C.G. Gd. II).

FIG. 5.-Abnormal ballistocardiogram preceding infarction and not further affected by it. The upper records were taken four months after the onset of angina of effort; the electrocardiogram is normal but the ballistocardiogram is Grade II. Three months later infarction occurred with diagnostic changes in the foot lead but neither the severity of the symptoms nor the ballistocardiographic appearance were altered. 
TABLE VII

Cases of Coronary Disease Complicated by Hypertension (Diastolic B.P.>104 mm. Hg)

\begin{tabular}{c|c|c|c|c|c|c|c|c}
\hline \multirow{2}{*}{$\begin{array}{c}\text { No. of } \\
\text { cases }\end{array}$} & \multicolumn{4}{|c|}{ Electrocardiogram } & \multicolumn{4}{c}{ Ballistocardiogram } \\
\cline { 2 - 7 } & Normal & $\begin{array}{c}\text { Non- } \\
\text { specific }\end{array}$ & $\begin{array}{c}\text { Suspected } \\
\text { Infarction }\end{array}$ & Infarct & Normal & Gd. I & Gd. II & Gd. III \\
\hline 41 & $\begin{array}{c}11 \\
(26 \cdot 8 \%)\end{array}$ & $\begin{array}{c}19 \\
(46 \cdot 3 \%)\end{array}$ & $\begin{array}{c}6 \\
(14 \cdot 6 \%)\end{array}$ & $\begin{array}{c}5 \\
(12 \cdot 3 \%)\end{array}$ & $\begin{array}{c}5 \\
(12 \cdot 3 \%)\end{array}$ & $\begin{array}{c}13 \\
(31 \cdot 7 \%)\end{array}$ & $\begin{array}{c}19 \\
(46 \cdot 3 \%)\end{array}$ & $\begin{array}{c}4 \\
(9 \cdot 7 \%)\end{array}$ \\
\hline
\end{tabular}

TABLE VIII

The Ballistocardiogram by Contrast with the Clinical State on ReVIEW In SiX to TWeLVE Months Time

\begin{tabular}{c|c|c|c|c}
\hline \multirow{2}{*}{$\begin{array}{c}\text { No. of } \\
\text { cases }\end{array}$} & Ballistocardiogram & \multicolumn{3}{|c}{ Clinical state } \\
\cline { 3 - 5 } & & Unchanged & Better & Worse \\
\hline 40 & Unchanged & 26 & 9 & 5 \\
15 & Improved & 11 & 4 & 0 \\
16 & Worse & 9 & 1 & 6 \\
\hline
\end{tabular}

of ballistocardiographic changes, but in only one case did the ballistocardiogram alter inversely to the clinical state (Table VIII).

Approximately one-fifth of all patients had a normal ballistocardiogram. Although most usually found in patients relatively fit, an almost normal ballistocardiogram was occasionally recorded despite severe disability.

Case Report (252). A man of 52 had suffered from severe angina of effort and high blood pressure for over five years. Six months previously he had an electrocardiographically proven myocardial infarct. He was admitted to hospital in left ventricular failure with gallop rhythm and crepitations at both lung bases. The blood pressure was $185 / 140 \mathrm{~mm}$. Hg. The electrocardiogram showed evidence of both posterior and anterior infarction but apart from an unusually large diastolic wave and rather high voltage $\mathbf{H}$ waves, the ballistocardiogram was within normal limits. $\mathrm{He}$ made an excellent recovery from the episode of left ventricular failure and his subsequent course will be watched with interest (Fig. 6).

Fourteen patients had both normal electrocardiograms and ballistocardiograms. Five were found to be symptom-free a year later and both records were still normal in four (in one the ballistocardiogram was inadvertently omitted): Two patients had deteriorated symptomatically but both records remained normal. One patient was unchanged but the ballistocardiogram was now Grade I abnormal. The other six patients have not been seen again.

Controls. Of the 38 controls, the ballistocardiogram was normal in 37 and Grade $I$ in one. Seventeen of these patients were under fifty and 21 between fifty and fifty-nine.

\section{Discussion}

The ballistocardiogram and the electrocardiogram measure entirely different aspects of cardiac function, neither being specifically related to disease of the coronary arteries. The difference in the electrocardiographic and ballistocardiographic findings in the various clinical groups is an expression of this fact. The relation between the two methods of investigation has been dramatically described by Starr. In analogy to a motor engine he said the electrocardiogram may be 
I

II

III

$\mathrm{R}$

L

F
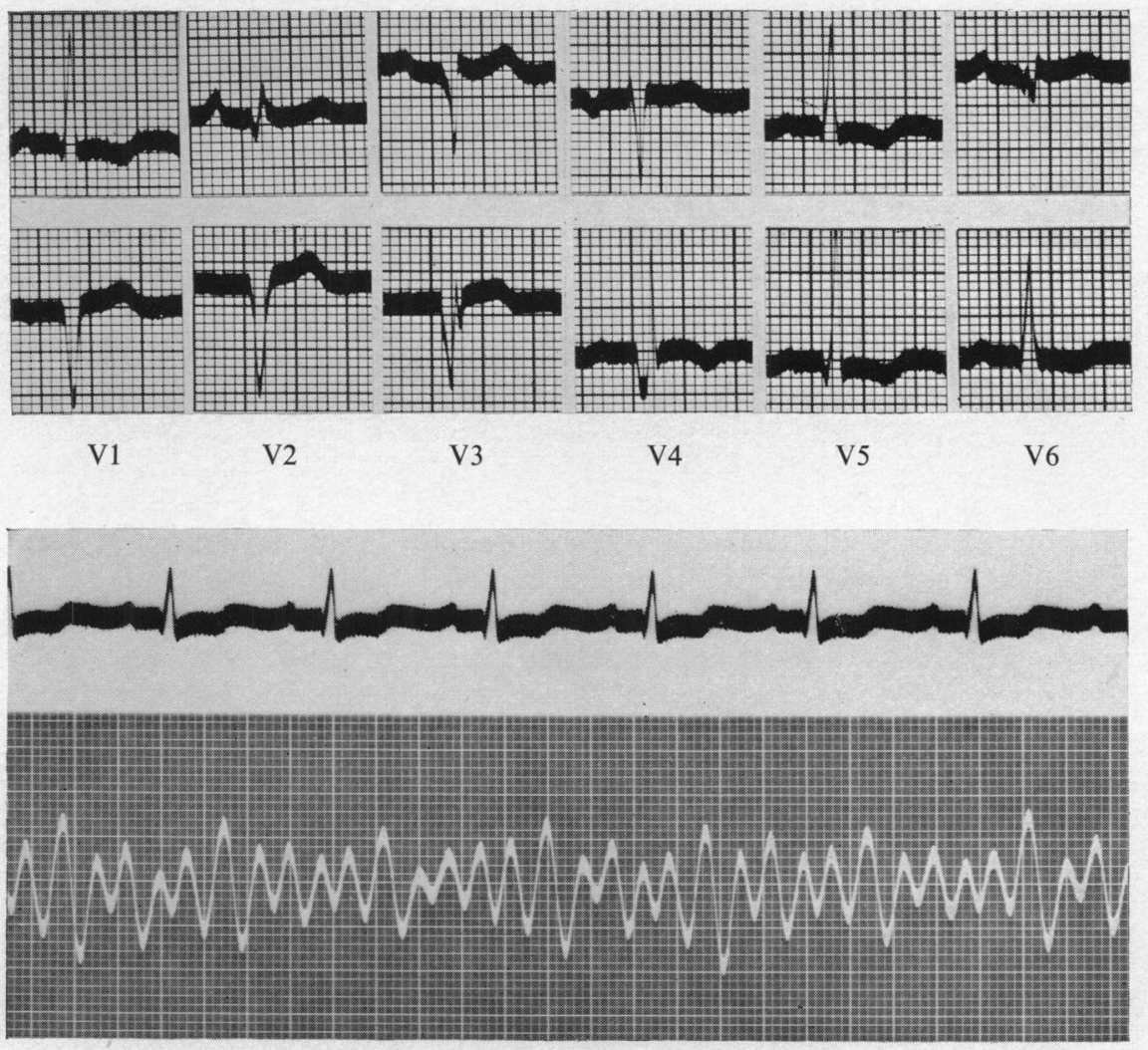

FIG. 6.-Relatively normal ballistocardiogram despite severe myocardial disease. There is electrocardiographic evidence of both posterior and anterior infarction and a history of left ventricular failure. The ballistocardiogram shows only minor abnormalities with large $\mathbf{H}$ waves in the expiratory complexes.

regarded as estimating the strength of the spark; the ballistocardiogram the resulting explosion. This concept of the ballistocardiogram as a measure of the strength of contraction offers an acceptable explanation for the fairly constant results in the various groups for it is reasonable to expect contractile power to depend as much upon the general state of the myocardium as upon the occurrence of specific infarction. The higher incidence of very abnormal records in the immediate postinfarction period suggests that infarction may initiate a long period of myocardial dysfunction and offers a further reason for gradual convalescence of patients with this condition. It might be anticipated that the ballistocardiogram would be more closely related to the severity of the disease state than the electrocardiogram and the results in the different groups tend to support this concept. It is possible, as Starr (1952) has suggested, that the ballistocardiogram may prove to have some prognostic value, but more follow-up studies are required to clarify this point.

The overall results, which show that approximately 80 per cent of patients with coronary arterial disease have an abnormal ballistocardiogram, correspond with the results reported by other workers (Chensky et al., 1951; Moser et al., 1952; Scarborough et al., 1952; Jacob, 1954). Chesky et al. and Scarborough et al. also divided their patients according to whether there had been infarction or not and found similar ballistocardiographic results in the two groups. Brown et al. (1950) reported abnormal ballistocardiograms in all 27 cases of typical angina pectoris irrespective of the 
electrocardiogram but the relation to infarction was not specifically stated. All these authors concluded that the ballistocardiogram was a useful diagnostic aid.

The higher proportion of abnormal ballistocardiograms in the older age groups has also been commented on by Pordy et al. (1951), Scarborough et al. (1952) and Starr and Mayock (1948). Scarborough et al. (1952) concluded that the increase was simply related to age and paralleled the changes found in normal subjects: they suggested that an abnormal ballistocardiogram had little or no significance in patients over 60 years of age. Starr and Mayock (1948) found an increasing proportion of abnormal records in presumptively normal men up to the age group 50-59; in that decade it reached 25 per cent, remaining constant thereafter: they felt that the group studied was in fact selected and biased in favour of heart disease. In a careful follow-up study of 80 healthy adults over ten to fifteen years, Starr and Hildreth (1952) did not observe any qualitative change in the ballistocardiogram with advancing years; there was a general diminution in the amplitude of I-J; compared with young adults there was an average decrease of 30 per cent over the age of forty, of 40 per cent over fifty, and of 49 per cent over sixty. They concluded that this was merely an expression of the fact that the ageing heart " lifts its load more slowly". We lack adequate controls over the age of sixty, but our results in normal subjects in the sixth decade suggests that Starr and Hildreth's view is correct. Scarborough et al. do not give their ballistocardiographic criteria so that detailed comparison is impossible, but it appears likely that they were regarding this physiological diminution in the size of the complexes with advancing age as abnormal. Jacobs (1954) has suggested that peripheral arteriosclerosis may be as important as coronary artery disease in the production of abnormal graphs. Three of our controls had what was considered to be an excessive degree of generalized atherosclerosis, but all had normal ballistocardiograms. Starr and Mayock (1948) believe that when qualitative changes are present it is probable that the coronary circulation is diseased although the subject may appear to be in good health, an opinion also put forward by Brown et al. (1950) with which we are inclined to concur.

In cases of systemic hypertension the diminished likelihood of finding unequivocal electrocardiographic evidence of infarction renders the ballistocardiogram particularly useful in the elucidation of the nature of chest pain. Abnormal ballistocardiograms were found just as often amongst the group with normal, non-specific or left ventricular electrocardiograms as those with definite evidence of ischæmia or infarction. The finding of a normal ballistocardiogram in 11 cases and in all four of the control group with diastolic blood pressures over $105 \mathrm{~mm}$. $\mathrm{Hg}$ excludes the possibility that qualitative changes may be produced solely by the high peripheral resistance.

It is concluded that the ballistocardiogram is a useful diagnostic aid in cases of suspected coronary arterial disease. It is, however, dependent upon cardiac force and, in the way we have used it, is an indirect measure of the form of the cardiac ejection curve. It must be stressed that abnormalities of cardiac ejection may only be ascribed to coronary disease if other causes have been excluded. Although it appears to be a somewhat more sensitive index of coronary disease than the electrocardiogram, a normal ballistocardiogram does not exclude coronary disease. It will never supplant the electrocardiogram for it measures a different aspect of cardiac function, but even in the present early stage of its development it is a valuable complementary investigation. Of our patients with undoubted coronary disease 37 per cent had a normal electrocardiogram and 19 per cent had a normal ballistocardiogram: only 7 per cent had both a normal electrocardiogram and ballistocardiogram. It is of especial value in cases of cardiac pain confined to effort and in cases complicated by systemic hypertension. It has the additional merits of being perfectly safe, easily performed, and applicable to seriously ill patients.

\section{SUMMARY}

The results of ballistocardiographic studies in 197 cases of clinical coronary arterial disease and 38 presumptively normal controls are reported and contrasted with the clinical and electrocardiographic data. A high-frequency undamped ballistocardiograph of the Starr type was used. 
The ballistocardiogram was abnormal in 159 cases $(81 \%$ ). It was normal in the remainder and in 37 controls. The electrocardiogram showed changes of infarction in 77 cases $(40 \%)$ and non-specific abnormalities in a further $47(24 \%)$. It was normal in 73 cases $(37 \%)$ and in all 38 controls.

The pattern of the ballistocardiographic results was fairly uniform irrespective of clinical or electrocardiographic evidence of infarction or complicating systemic hypertension. There was a tendency to a higher proportion of grossly abnormal ballistocardiograms in the immediate postinfarction phase.

Abnormal records occurred more often in the older age groups and were an expression of a higher incidence of generalized coronary disease.

The ballistocardiogram is a useful investigation in cases of suspected coronary disease, especially in cases with cardiac pain confined to effort or with systemic hypertension, for in these cases the electrocardiogram is frequently normal. Only 7 per cent of all cases had both a normal ballistocardiogram and electrocardiogram.

Our thanks are due to Professor Crighton Bramwell and Dr. Morgan Jones for their criticism and advice and for permission to examine patients under their care.

The ballistocardiographic table and the electronic recording apparatus were constructed by Mr. V. Attree of the Department of Electrical Engineering of the College of Technology, Manchester University.

\section{REFERENCES}

Abrahamson, E. (1933). Scand. Arch. Physiol., 66, 191.

Brown, H. H., Hoffman, M. J. and de Lalla, V. (1950). Circulation, 1, 132.

Chesky, K., Moser, M., Taymor, R. C., Pordy, L., and Master, A. M. (1951). Amer. Heart J., $42,327$.

Dock, W. (1954). Amer. J. med. Sci., 227, 125.

Gubner, R. S., Rodstein, H., and Ungerleider, H. E. (1953). Circulation, 7, 268.

Hamilton, W. F., Dow, P., and Remington, J. W. (1945). Amer. J. Physiol., 144, 557.

Henderson, Y. (1905). Amer. J. Physiol., 14, 287. Quoted by: Starr, I., Rawson, A. J., Schroeder, H. A., and Joseph, N. R. (1939). Amer. J. Physiol., 127, 1.

Jacobs, H. D. (1954). Brit. Heart J., 16, 79.

Levy, R. L., Bruenn, H. G., and Williams, N. E. (1940). Amer. Heart J., 19, 639.

Master, A. M. (1935). Amer. Heart J., 10, 495.

Moser, M., Pordy, L., Chesky, K., Taymor, R. C., and Master, A. M. (1952). Circulation, 6, 402.

Nickerson, J. L., and Curtis, H. J. (1944). Amer. J. Physiol., 142, 1.

Pordy, L., Taymor, R. C., Moser, M., Chesky, K., and Master, A. M. (1951). Amer. Heart J., $42,321$.

Rappaport, M. B., Sprague, H. E., and Thompson, W. B. (1953). Circulation, 7, 229.

Scarborough, W. R., Mason, R. E., Davis, E. W., Singewald, M. L., Baker, B. M., and Lors, S. H. (1952). Amer. Heart J., 44, 645.

Snow, P. J. D. (1955). Personal Communication.

Starr, I. (1952). Ann. intern. Med., 37, 839.

—, Braunstein, J. R., Dock, W., Gubner, R., Hamilton, W. F., Nickerson, J. L., Rappaport, M. B., Scarborough, W. R., and Smith, J. E. (1953). Committee on Ballistocardiograph Terminology. Circulation, 7, 929.

- , and Hildreth, E. A. (1952). Circulation, 5, 481.

-, Horwitz, O., Mayock, R. L., and Krumbhaar, E. G. (1950). Circulation, 1, 1073.

-, and Mayock, R. L. (1948). Amer. J. med. Sci., 215, 631.

- Rawson, A. J., Schroeder, H. A., and Joseph, N. R. (1939). Amer. J. Physiol., $127,1$.

- , and Schnabel, T. G. (1954). J. Clin. Invest., 33, 10.

- and Wood, F. C. (1943). Amer. Heart J., 25, 81.

Tannenbaum, O., Schack, J. H., and Vesell, H. (1952). Circulation, 7, 321.

- , Vesell, H., and Schack, J. H. (1954). Amer. Heart J., 48, 562.

Thompson, W. B., Rappaport, M. B., and Sprague, H. B. (1953). Circulation, 7, 321.

Wade, E. G., and Morgan Jones, A. (1951). Brit. Heart J., 3, 319. 